\title{
PENGARUH PENGGUNAAN SANDAL DROP FOOT TERHADAP PERBAIKAN POLA JALAN PENDERITA DROP FOOT AKIBAT KUSTA DI RUMAH SAKIT KUSTA SUMBERGLAGAH MOJOKERTO
}

\section{Gatot Sunarto}

RSUD. Sumber Glagah Mojokerto Jawa Timur, Indonesia

Email: davio34@gmail.com

\begin{abstract}
Abstrak
Pada penanganan Drop Foot akibat kusta, Ortotik Prostetik dapat memberikan pelayanan dalam bentuk ortosis yaitu Sandal Drop Foot, yang bertujuan untuk mengurangi derajad Drop Foot pada ankle joint yang disebabkan oleh penurunan tonus otot dorsal fleksor. Pengambilan sampel dilakukan dengan cara purposive sampling. Jumlah sampel terdiri dari 10 penderita Drop Foot akibat kusta di Rumah Sakit Kusta Sumberglagah Mojokerto. Instrumen yang digunakan adalah Rivermead Visual Gait Assessment form, peralatan video gait analysis ( handycam, goniometre, alat tulis). Sandal Drop Foot berpengaruh besar pada pasien kusta yang mengalami drop foot dalam memperbaiki pola jalan dibandingkan tanpa saat mengunakan Sandal Drop foot. Sandal Drop foot adalah suatu alat bantu atau alat koreksi untuk mencegah drop foot berkepanjangan atau mencegah kecacatan lebih lanjut, tetapi tidak bisa menyembuhkan dan mengembalikan normal pada penderita drop foot akibat kusta. Tujuan penelitian ini adalah untuk mengetahui Pengaruh Pengunaan Sandal Drop Foot Terhadap Perbaikan Pola Jalan Penderita Drop Foot Akibat Kusta. Penelitian ini menggunakan desain penelitian" Quasi experiment pre post test with out control desain" one groups pre and post desain, dimana dalam penelitian ini hanya terdapat satu kelompok subyek teliti yang akan diukur pola jalannya sebelum dan sesudah diberikan perlakuan. Dari uji alternatif Wilcoxon diperoleh nilai signifikansi dengan value $p=0.004$, karena $p<0.05$, maka dapat dikatakan terdapat pengaruh pengunaan Sandal Drop Foot terhadap perbaikan pola jalan penderita drop foot akibat kusta.
\end{abstract}

Kata Kunci: Sandal drop foot; kusta; pola jalan; ortosis

\section{Abstract}

In handling Drop Foot due to leprosy, Prosthetic Orthotics can provide services in the form of ortosis, namely Sandal Drop Foot, which aims to reduce the drop foot in the ankle joint caused by a decrease in flexor dorsal muscle tone. Sampling is done by purposive sampling. The sample count consisted of 10 drop foot sufferers due to leprosy at Sumberglagah Mojokerto Leprosy Hospital. The instrument used is Rivermead Visual Gait Assessment form, video gait analysis equipment (handycam, goniometre, stationery). Drop Foot sandals have a big effect on leprosy patients who experience drop foot in improving road patterns compared to without when using Drop foot sandals. Drop foot sandals are sutu aids or correction tools

\begin{tabular}{ll}
\hline How to cite: & Sunarto, G., (2021) Pengaruh Penggunaan Sandal Drop Foot Terhadap Perbaikan Pola Jalan \\
& Penderita Drop Foot Akibat Kusta Di Rumah Sakit Kusta Sumberglagah Mojokerto, Syntax Idea, \\
& 3(12), https:// doi.org/10.36418/syntax-idea.v3i12.1618 \\
E-ISSN: & 2684-883X \\
Published by: & Ridwan Institute
\end{tabular}


to prevent prolonged drop foot or prevent further disability, but can not cure and restore normal in people with drop foot due to leprosy. The purpose of this study is to find out the Effect of Using Drop Foot Sandals On Improving Road Patterns of People With Drop Foot Due to Leprosy. This study uses the research design" Quasi experiment pre post test with out control design" one groups pre and post design, where in this study there is only one group of conscientious subjects who will be measured the pattern of the path before and after being given treatment. From the alternative test Wilcoxon obtained a value of significance with a value of $p=0.004$, because $p<0.05$, it can be said that there is an effect on the use of Drop Foot Sandals on improving the road pattern of drop foot sufferers due to leprosy.

Keywords: Sandal drop foot; leprosy; road patterns; ortosis

Received: 2021-11-22; Accepted: 2021-12-05; Published: 2021-12-20

\section{Pendahuluan}

Program jaminan kesehatan nasioanal (JKN) merupakan program pemerintah di bidang kesehatan tahun 2014 adalah yang di selenggarakan oleh Badan Penyelenggara Jaminan Sosial (BPJS) sesuai UU No 40 tahun 2004. Dengan Program JKN ini diharapkan terwujudnya Indonesia sehat. Jaminan Kesehatan menurut UU SJSN diselenggarakan secara nasional berdasarkan prinsip asuransi sosial dan prinsip ekuitas, dengan tujuan menjamin agar peserta memperoleh manfaat pemeliharaan kesehatan dan perlindungan dalam memenuhi dasar kesehatan (http://bpjs-kesehatan.go.id/, 2014).

Misi program kesehatan nasional untuk pengendalian kusta adalah Indonesia bebas kusta tahun 2010 dengan tujuan menyembuhkan dan meningkatkan kualitas hidup penderita kusta. Pada tahun 2009 program pengendalian kusta telah berhasil mengobati dan menyembuhkan 375.119 penderita dengan Multi-Drug Therapy (MDT) sejak 1990 dan telah menurunkan $80 \%$ jumlah penderita dari 107.271 pada tahun 1990 menjadi 21,026 penderita pada tahun 2009. Namun beban akibat kecacatan tingkat 2 masih tinggi dan ditemukan tiap tahunnya di Indonesia. Secara komulatif sejak tahun $1990-$ 2009, terdapat sekitar 30.000 kasus cacat tingkat 2 (mata tidak bisa menutup karena syarafnya terganggu, jari tangan atau kaki bengkok (kiting), luka pada telapak tangan dan kaki akibat mati rasa, kelemahan pada kaki akibat terganggunya saraf motorik) (Fatmawati, 2018).

Penyakit kusta adalah penyakit menular, menahun dan disebabkan oleh kuman kusta (Mycobacterium leprae) yang menyerang saraf tepi, kulit dan jaringan tubuh lainnya kecuali susunan saraf pusat (Ariana, 2016). Istilah kusta berasal dari bahasa sansekerta, yakni Kustha berarti kumpulan gejala gejala kulit secara umum. Kusta adalah penyakit kronik yang pertama kali menyerang susunan saraf perifer, selanjutnya dapat menyerang kulit, mukosa (mulut), saluran pernapasan bagian atas, kemudian dapat keorgan lain kecuali susunan saraf pusat (Kosasih \& Tieu, 2007). Kusta menyebabkan fungsi dari system saraf tepi terganggu, diantaranya fungsi sensorik, motorik, dan otonom. Terganggunya tiga fungsi sistem saraf tepi ini, dapat menimbulkan kecacatan. Kecacatan kusta adalah keadaan abnormal dari fisik dan fungsi 
tubuh serta hilangnya beberapa struktur dan fungsi tubuh yang diakibatkan oleh penyakit kusta (RI, 2020). Salah satu kejadian kecacatan komplikasi kusta adalah terjadinya drop foot.

Indonesia menempati urutan ke 3 setelah India dan Brazil dalam hal penyumbang jumlah penderita kusta didunia. Di Jawa Timur, jumlah penderita kusta menempati peringkat pertama terbanyak di seluruh Indonesia. Tercatat pada tahun 2011, jumlah penderita kusta yang baru ada5.000 jiwa atau sekitar 30\% dari jumlah seluruh penderita baru di Indonesia. Di Rumah Sakit Kusta Sumberglagah angka kejadian penderita kusta yang mengalami kecacatan drop foot pada tahun 2013 sekitar 70 orang (Oktaviana, 2021).

Timbulnya cacat kusta terjadi terutama akibat adanya kerusakan saraf (sensorik, motorik, otonom). Kelumpuhan fungsi motorik termasuk cacat primer. Cacat primer ialah kelompok cacat yang disebabkan langsung oleh aktivitas penyakit, terutama kerusakan akibat respon jaringan terhadap kuman Leprae. Kelumpuhan motorik dapat menyebabkan kelemahan pada anggota gerak. Kelemahan gerak pada kaki dapat menimbulkan gangguan berjalan, yang pada akhirnya bisa menyebabkan terjadinya drop foot karena tidak adanya upaya untuk menangani kelemahan gerak pada kaki (Widyaningsih, 2019).

Ortotik Prostetik merupakan upaya pelayanan kesehatan profesional, yang bertanggung jawab atas kesehatan klien yang mengalami deformitas, dengan memberikan layanan berupa (1) pembuatan alat bantu aktivitas Anggota Gerak Atas, alat bantu mobilitas Anggota Gerak Bawah, dan pembuatan alat penguat/penyangga tubuh, (2) pembuatan alat pengganti anggota gerak tubuh (Utomo, Setyawan, \& Fathi, 2018).

Drop Foot pada kusta memerlukan penanganan karena dapat menganggu fungsi dan pola jalan penderita. Salah satu penanganannya adalah dengan fisioterapi dan pengunaan alat bantu (orthosis). Alat bantu atau orthosis yang sesuai diagnosa drop foot adalah Ankle Foot Orthosis (AFO). AFO adalah sebuah orthosis yang digunakan untuk pengobatan gangguan atau kelainan di pergelangan kaki dan area bawah sendi lutut. AFO untuk kasus drop foot di sebut AFO posterior leaf spring. Pada kasus drop foot yang terjadi pada penderita kusta, penggunaan AFO harus di modifikasi, karena pada penderita juga disertai dengan kerusakan fungsi saraf otonom, sehingga AFO untuk drop foot tidak bisa memfiksasi seluruh bagian area di bawah lutut. Modifikasi juga diperlukan karena terkadang terdapat luka pada kaki ( ulkus plantaris pedis) akibat kerusakan fungsi saraf sensorik di bagian kaki yang mengalami drop foot atau yang sebelahnya yang tidak mengalami drop foot. Maka modifikasi AFO yang tepat adalah Sandal drop foot-AFO disesuaikan dengan keadaan penderita kusta diharapkan mampu meningkatkan keefektifan fungsi berjalan penderita kusta.

\section{Metode Penelitian}

Pada Pengaruh Pengunaan Sandal Drop Foot Terhadap Perbaikan Pola Jalan Penderita Drop Foot Akibat Kusta Di Rumah Sakit Kusta Sumberglagah Mojokerto ini 
peneliti menggunakan jenis penelitian "Quasi experiment pre post test with out control desain" dengan model pendekatan pre-test post-test one group design yaitu eksperimen yang dilakukan pada satu kelompok tanpa kelompok pembanding. "Quasi experiment pre post test with out control desain" adalah study experimental yang dalam mengontrol situasi penelitian menggunakan cara non randomisasi (Warneke, Last, Liebowitz, \& Pister, 2001). Sedangkan maksud dari pre-test post-test one group design adalah penelitian ini dilakukan sebanyak dua kali yaitu sebelum eksperimen (pre-test) dan sesudah ekperimen (post-test) dengan satu kelompok subjek. Penelitian ini bertujuan untuk mempelajari hubungan antara Drop Foot dengan Sandal drop foot dan tanpa Sandal drop foot dengan cara mengamati pengaruh fase jalan selama berjalan. Data yang berasal dari penelitian ini bermanfaat untuk menaksir besarnya kebutuhan di bidang pelayanan kesehatan dan populasi tersebut (Ariyanti \& Muslimin, 2015).

Data yang terkumpul dimasukkan ke dalam komputer, dilakukan seleksi data, pemberian koding dan tabulasi. Analisis dilakukan secara deskriptif dimana variable dengan skala kontinyu dideskriptifkan sebagai rerata dan simpangan baku (SB). Untuk mengetahui hasil perbandingan fungsional pada kelompok pengguna sandal drop foot dilakukan uji hipotesis. Uji hipotesis akan menggunakan uji beda (t test) dengan $\alpha=5 \%$ bila memenuhi uji prasyarat analis. Penetuan menolak atau menerima Ho, didasarkan pada $\mathrm{p}$ value yang tampak pada output uji tersebut apabila $\mathrm{p}$ value $<0,05$ maka Ho ditolak, atau sebaliknya. Apabila p value. 0,05 maka Ho diterima. Namun bila tidak memenuhi persyaratan analisis dilakukan uji hipotesis dengan non parametric.

\section{Hasil dan Pembahasan}

\section{A. Hasil Penelitian}

\section{Analisis Univariat (Descriptive)}

Subyek dalam penelitian ini penderita kusta yang mengalami drop foot dengan fleksebilitas pada ankle joint. Jumlah sample pada penelitian ini adalah 10 sample yang mendapat intervensi alat bantu ortosis dari Rumah Sakit Kusta Sumberglagah Mojokerto instalasi Rehabilitasi medik unit Ortotik prostetik.

\section{Tabel 1}

Distribusi Frekuensi Umur Responden

\begin{tabular}{lllll}
\hline & Min & Max & Mean & Std. Deviation \\
\hline Umur & 30 & 60 & 44.50 & 11.404 \\
\hline
\end{tabular}

Umur dari 10 responden yang di teliti berkisar antar umur 30 tahun sampai 60 tahun. Umur responden tertua 60 tahun, termuda 30 tahun, dan rata-rata berumur 44,50 tahun (Astrid, Putranti, \& Purwanti, 2018).

Karakteristik subyek penelitian berdasarkan jenis kelamin adalah: (1) pria sebanyak 7 subyek (70\%), (2) wanita sebanyak 3 subyek (30\%). Karakteristik 
subyek penelitian berdasarkan dapat dilihat pada tabel berikut (Afriyeni \& Sartana, 2017).

Tabel 2

Distribusi Frekuensi Jenis Kelamin

\begin{tabular}{lll}
\hline \multirow{2}{*}{ Klasifikasi jenis kelamin } & \multicolumn{2}{l}{ Kelompok 1 } \\
\cline { 2 - 3 } & $\mathrm{N}$ & $\%$ \\
\hline Pria & 7 & 70 \\
Wanita & 3 & 30 \\
\hline Jumlah & 10 & 100 \\
\hline
\end{tabular}

Pengumpulan data tahap I merekan tes jalan pada subyek dengan tanpa menggunakan Sandal Drop Foot kemudian dilakukan tes analisia pola jalan. Pengumpulan data tahap II merekam tes jalan pada pasien dengan menggunakan Sandal Drop Foot kemudian dilakukan tes analisa pola jalan (Umaroh, 2018).

Tahap terakhir pengelolaan data dengan cara membandingkan nilai rerata pola jalan subyek tidak menggunakan Sandal Drop Foot dengan pola jalan subyek menggunakan Sandal Drop Foot. Dalam penelitian ini peneliti menggunakan instrument "Rivermead Visual Gait Assessment form" yang menilai gerakangerakan fase dalam satu silkus berjalan. Dalam tahap stance fase terdiri dari gerakan-gerakan sebagai berikut:

Hasil Pengamatan Gerakan Trunk flexed / extended terjadi perubahan pre test dan post test pada 6 responden, selebihnya nilainya tetap sama pre test dan post test. Sehingga penggunaan sandal drop foot cukup berpengaruh memperbaiki pola pada fase gerakan ini.

\section{Analisis Bivariat}

Pengaruh pola jalan diukur dengan penarikan rata - rata, yang hasilnya erupakan data rasio. Untuk mengeahui ada tidaknya pengaruh nilai rata - rata saat tidak memakai Sandal Drop Foot dan saat pemakaian Sandal Drop Foot dilakukan uji beda dengan menggunakan paired sample T - Test.

Sebelum data di analisis dengan uji Paired Sample T - Test, terlebih dahulu dilakukan uji normalitas untuk memastikan bahwa data berdistribusi normal. Dalam penelitian ini jumlah sample kurang dari 30 maka dianggap data berdistribusi tidak normal sehingga peneliti tidak menggunakan uji normalitas, sehingga peneliti menggunakan alternative uji Wilcoxon.

\section{Tabel 1}

\section{Ranks}

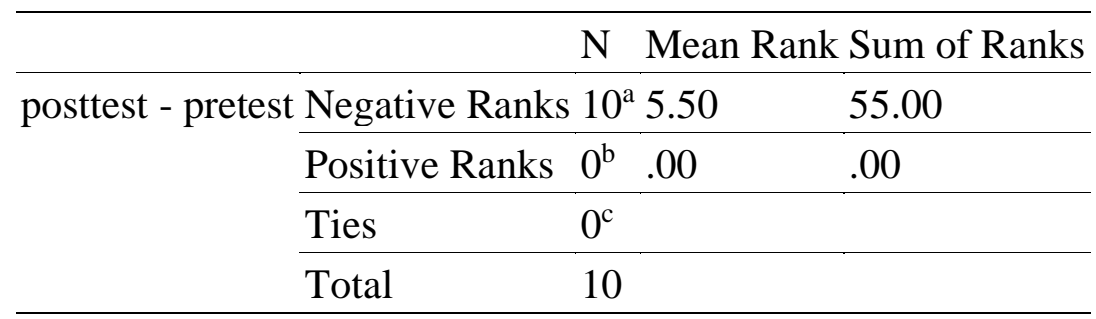

a. posttest < pretest 
b. posttest $>$ pretest

c. posttest $=$ pretest

\begin{tabular}{ll}
\hline \hline & POST TEST - PRE TEST \\
\hline$Z$ & $-2,842^{\text {a }}$ \\
\hline Asymp. Sig. (2-tailed) &, 004 \\
\hline
\end{tabular}

Dari uji alternatif Wilcoxon diperoleh nilai signifikansi dengan value $\mathrm{p}=$ 0.004, karena $\mathrm{p}<0.05$, maka dapat dikatakan terdapat pengaruh terhadap perbaikan pola jalan antara pre test dan post test.

\section{B. Pembahasan}

Pada analisis univariat diketahui bahwa subyek berumur antara 30 hingga 60 tahun, dengan rata-rata 30 tahun dengan Standard Deviasi 1,334. Ditinjau dari jenis kelamin, hasil penelitian menunjukkan bahwa subyek penelitian ini didominasi oleh kaum laki - laki.

Hasil analisis bivariat menunjukkan bahwa pada sisi perlakuan Sandal Drop Foot menunjukkan ada pengaruh secara signifikan terhadap perbaikan pola jalan pasien drop foot dibandingkan dengan subyek yang tidak memakai Sandal Drop Foot. Hasil pengamatan dengan Rivermead Visual gait assessment Form tanpa mengunakan Sandal Drop Foot dan mengunakan Sandal Drop Foot dan diolah dalam data statistk menunjukan skor yang signifikan berkurang saat pengamatan dengan menggunakan Sandal Drop Foot . Dalam penelitian ini dilakukan uji statistik non parametrik dan menunjukkan bahwa pemakaian Sandal Drop Foot pada kondisi drop foot akibat kusta terhadap perbaikan pola jalan terdapat pengaruh yang signifikan $(\mathrm{p}=0,004<0,005)$, artinya saat pemakaian Sandal Drop Foot terjadi perbaikanan pola jalan pada pasien drop foot akibat kusta. Hal ini dikarenakan desain Sandal Drop Foot yang membatasi Plantar Fleksi pada Ankle dalam posisi terkoreksi $90^{\circ}$. Sehingga dari segi biomekanik pada saat GRF bekerja dari bawah menyebabkan dorsi fleksi dan akan dikontrol oleh dinding belakang cup dan strap sehingga mencegah dorsal fleksi yang berlebihan dan axis knee dengan GRF line letaknya bertepatan maka knee akan terkunci atau bisa ekstensi full dan menyebabkan GRF line berada tepat di axis hip sehingga hip dalam posisi ekstensi normal (ARI, 2017).

Perubahan pola jalan menggunakan sandal drop foot berpengaruh pada hampir semua fase pola jalan yaitu pada fase phase sebagai berikut: Trunkflexed / extended cukup berpengaruh berkurang dengan pengunaan sandal drop foot, Trunk side flexed kurang berpengaruh karna hanya 4 responden yang mengalami perubahan, Trunk and pelvis: lateral displacement cukup berpengaruh berkurang dengan pengunaan sandal drop foot, Contralateral drop sangat berpengaruh dengan berkurang gerakan pada pengunaan sandal drop foot, Hip extension decreased sangat berpengaruh dengan berkurang gerakan pada pengunaan sandal drop foot, Knee flexion excessive sangat berpengaruh dengan berkurang gerakan pada pengunaan sandal drop foot, Knee 
extension excessive sangat berpengaruh dengan berkurang gerakan pada pengunaan sandal drop foot, Ankle in excess plantar flexion sangat berpengaruh dengan berkurang gerakan pada pengunaan sandal drop foot, Ankle in excess dorsi flexion sangat berpengaruh dengan berkurang gerakan pada pengunaan sandal drop foot, Inversion excessive sangat berpengaruh dengan berkurang gerakan pada pengunaan sandal drop foot, Plantar flexion decreased at toe-off sangat berpengaruh dengan berkurang gerakan pada pengunaan sandal drop foot. Sedangkan dalam fase swing gerakan-gerakan dirinci sebagai berikut: Trunk flexed sangat berpengaruh dengan berkurang gerakan pada pengunaan sandal drop foot, Trunk side flexed cukup berpengaruh dengan berkurang gerakan pada pengunaan sandal drop foot, Hike pelvis (elevation) sangat berpengaruh dengan berkurang gerakan pada pengunaan sandal drop foot, Backward rotation pelvis sangat berpengaruh dengan berkurang gerakan pada pengunaan sandal drop foot, Decreased hip flexion cukup berpengaruh dengan berkurang gerakan pada pengunaan sandal drop foot, Decreased knee flexion sangat berpengaruh dengan berkurang gerakan pada pengunaan sandal drop foot, Ankle in excess plantar flexion sangat berpengaruh dengan berkurang gerakan pada pengunaan sandal drop foot.

Pengaruh pengunaan sandal Drop foot ini juga menunjukan terjadinya perbaikan pada pola jalan pasien drop foot pada fase heel strike yang sebelumnya hilang saat pasien tanpa menggunakan Sandal Drop Foot dan saat pengunaan Sandal Drop Foot terdapat perbaikan adanya fase heel strike. Selain itu juga pada fase swing pasien drop foot tanpa mengunakan Sandal Drop Foot cenderung ankle terjadi plantar fleksi yang berlebihan mengakibatkan terjadinya kompensasi knee dan hip fleksi yang menghindari foot slap, sedangkan pada pasien yang mengunakan Sandal Drop Foot pada fase swing ini terjadi perbaikan dengan hilangnya knee dan hip fleksi yang disebabkan oleh fiksasi posisi ankle pada posisi 90 drajad. Keseimbangan pasien drop foot kusta yang berjalan tanpa Sandal Drop Foot dan mengunakan Sandal Drop Foot terlihat sekali lebih stabil pasien drop foot yang mengunakan Sandal Drop Foot dibandingkan tanpa mengunakan Sandal Drop Foot. Temuan ini senada dengan penelitian berjudul Pengaruh penggunaan posterior leaf spring ankle foot orthosis terhadap perbaikan pola jalan penderita drop foot akibat stroke (Ismail, 2019).

Penelitian ini diharapkan dapat memberikan informasi baru kepada para praktisi Ortotis Prostetis. Informasi yang dihadapkan adalah tentang penggunaan Sandal Drop Foot pada kasus Drop Foot akibat kusta, sehingga dapat digunakan sebagai bahan acuan lebih lanjut di dalam melaksakan pelayanannya kepada masyarakat serta dapat mendukung perkembangan ilmu ortotik prostetik di Indonesia.

\section{Kesimpulan}

Penelitian ini dilakukan dengan tujuan untuk mengetahui pengaruh Sandal Drop Foot terhadap perbaikan pola jalan panderita drop foot akibat kusta. Dari hasil 
penelitian ini dapat diambil kesimpulan bahwa penggunaan Sandal Drop Foot berpengaruh terhadap perbaikan pola jalan pada pasien drop foot akibat kusta dan keseimbangan berjalan pasien lebih baik saat memakai Sandal Drop Foot dibandingkan tanpa mengunakan Sandal Drop Foot.

\section{BIBLIOGRAFI}

Afriyeni, Nelia, \& Sartana, Sartana. (2017). Gambaran Tekanan Dan Beban Yang Dialami Oleh Keluarga Sebagai Caregiver Penderita Psikotik Di Rsj Prof. HB Sa'Anin Padang. Jurnal Ecopsy, 3(3).Google Scholar

Ari, Cucuk Prasetyo. (2017). Pengaruh Terapi Senam Kaki Diabetik Terhadap Sensitivitas Kaki Pasien Diabetes Melitus Tipe 2 Di Wilayah Kerja Puskesmas Babadan Kabupaten Ponorogo. Stikes Bhakti Husada Mulia. Google Scholar

Ariana, Vivin Istya. (2016). Faktor-Faktor Yang Berhubungan Dengan Pencarian Pengobatan Pada Penderita Kusta Multy Bacillary (Mb) Di Kabupaten Pati Tahun 2015. Universitas Negeri Semarang. Google Scholar

Ariyanti, Ariyanti, \& Muslimin, Zidni Immawan. (2015). Efektivitas Alat Permainan Edukatif (APE) Berbasis Media dalam Meningkatkan Kemampuan Berhitung pada Anak Kelas 2 di SDN 2 Wonotirto Bulu Temanggung. Jurnal Psikologi Tabularasa, 10(1). Google Scholar

Astrid, Caroline, Putranti, Ismiralda Oke, \& Purwanti, Kurniasih Dwi. (2018). Perbedaan Tingkat Keparahan Psoriasis Pada Pasien Psoriasis Dengan Dan Tanpa Fokal Infeksi. Mandala Of Health: A Scientific Journal, 11(2), 80-94. Google Scholar

Fatmawati, Fatmawati. (2018). Sistem Pelayanan Rumah Sakit Dr. Tadjuddin Chalid terhadap Penyandang Kusta di Kecamatan Biringkanaya Daya Kota Makassar. Universitas Islam Negeri Alauddin Makassar. Google Scholar

Ismail, Moh Rizal. (2019). Kepribadian Tokoh Utama Dalam Novel Pasung Jiwa Karya Okky Madasari (Kajian Teori Psikoanalisis Sigmund Freud). University of Muhammadiyah Malang. Google Scholar

Kosasih, P. B., \& Tieu, A. K. (2007). Mixed film lubrication of strip rolling using O/W emulsions. Tribology International, 40(5), 709-716. Google Scholar

Oktaviana, Fabiola Tri Ruli. (2021). Determinan Interaksi Dan Partisipasi Sosial Penderita Kusta. Universitas Airlangga. Google Scholar

Ri, Kemenkes. (2020). Pedoman Pencegahan dan Pengendalian Coronavirus Disease (Covid-19). Kemenkes RI, 0-115. Google Scholar

Umaroh, Lilik. (2018). Pengaruh Diabetes Self Management Education (Dsme) Melalui 
Gatot Sunarto

Media Kalender Terhadap Kepatuhan Perawatan Kaki Klien Diabetes Mellitus Tipe 2 Di Balai Pengobatan Muhammadiyah Lamongan. Universitas Airlangga. Google Scholar

Utomo, Prasetyo Catur, Setyawan, Dwi, \& Fathi, Muhammad. (2018). Pengaruh penggunaan medial arch support terhadap penurunan derajat flat foot pada anak usia 8-12 Tahun. Jurnal Keterapian Fisik, 3(2), 58-62. Google Scholar

Warneke, Brett, Last, Matt, Liebowitz, Brian, \& Pister, Kristofer S. J. (2001). Smart dust: Communicating with a cubic-millimeter computer. Computer, 34(1), 44-51. Google Scholar

Widyaningsih, Tiyas Ayu. (2019). Asuhan Keperawatan Pada Pasien Dewasa Penderita Cva Dengan Masalah Keperawatan Ketidakseimbangan Nutrisi Di Ruang Aster RSUD Dr Harjono Ponorogo. Universitas Muhammadiyah Ponorogo. Google Scholar

\section{Copyright holder:}

Gatot Sunarto (2021)

\section{First publication right:}

Syntax Idea

This article is licensed under:

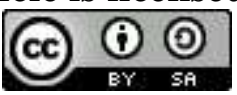

